Cita bibliográfica: Brito Carrasqueira, H.M.; Galvão Garcia, P.C. y Cotrim Carrasqueira, M. (2018). A internacionalização da hotelaria portuguesa para os mercados emergentes. Investigaciones Turísticas (15), pp. 34-48. http:// dx.doi.org/10.14198/INTURI2018.15.02

\title{
A internacionalização da hotelaria portuguesa para os mercados emergentes
}

\section{The internationalization of Portuguese hospitality for emerging markets}

\section{La internacionalización de la hotelería portuguesa para los mercados emergentes}

Helder Manuel Brito Carrasqueira. Universidad del Algarve, Portugal. hcarrasq@ualg.pt Paula Cristina Galvão Garcia. Universidad del Algarve, Portugal. pgarcia@ualg.pt Margarida Cotrim Carrasqueira. Universidadad de Lisboa, Portugal. margarida.carrasqueira@outlook.pt

\section{RESUMO}

O presente artigo procura explicar a internacionalização da hotelaria portuguesa nos países que se designam de economias emergentes latu sensu, situados em África e região nordeste do Brasil (abrange $72 \%$ das unidades hoteleiras e $93,8 \%$ das cadeias portuguesas com unidades hoteleiras no exterior). A partir de um inquérito junto dos diretores das unidades hoteleiras procurou-se caracterizar a afirmação no exterior através de três vetores: dimensões da internacionalização, forças competitivas e características da operação no exterior. Além das respostas ao: Porquê, o Quê, Como e para Onde, este artigo revela a posição face aos concorrentes, clientes, fornecedores, novas entradas e produtos substitutos; acresce as especificidades operacionais como o posicionamento face à distribuição, produto comercializado, opções de estandardização versus adaptação, entre outros. Procura-se ainda responder à seguinte questão através dos dados disponíveis: qual tem sido o ritmo de expansão da hotelaria portuguesa no exterior?

O processo de internacionalização ocorreu essencialmente para o espaço lusófono. Apenas um grupo apresenta um posicionamento multi-mercado, podendo ser considerado uma multinacional; os restantes têm um posicionamento multi-doméstico.

Palavras-chave: internacionalização; hotelaria portuguesa; economias emergentes.

\section{ABSTRACT}

This article seeks to explain the internationalization of the Portuguese hotel industry in countries which can be referred to as emerging economies in a broad sense, in Africa and northeastern Brazil (covering $72 \%$ of hotel units and $93.8 \%$ of Portuguese chains with hotels abroad). Based on a survey applied to directors of hotel units, the study attempts to characterize the presence 
abroad through three vectors: dimensions of internationalization, competitive strengths and characteristics of the operations abroad. In addition to the answers to Why, What, How and Where, this article also reveals the position with respect to competitors, customers, suppliers, new entrants and substitute products. It also addresses other aspects including operational specificities such as the positioning in relation to the distribution, marketed product, standardization versus adaptation options, among others. It also attempts to answer the following question from the available data: what has been the dynamic expansion of Portuguese hospitality abroad? The process of internationalization occurred essentially throughout the Lusophone space. Only one group has a multi-market positioning and can be considered as a multinational; the rest have a multi-domestic positioning.

Keywords: internationalization; Portuguese hotel industry; emerging economies.

\section{RESUMEN}

Este artículo trata de explicar la internacionalización de la industria hotelera portuguesa en los países conocidos en sentido amplio como economías emergentes, situadas en África y en el noreste de Brasil (cubre el $72 \%$ de unidades de hotel y el $93,8 \%$ de las cadenas portuguesas con hoteles en el extranjero). A partir de una encuesta entre los directores de las unidades hoteleras se buscó caracterizar la afirmación en el exterior a través de tres vectores: dimensiones de la internacionalización, fuerzas competitivas y características de la operación en el exterior. Además de dar respuesta a las cuestiones de ¿Por qué? ¿Qué? ¿Cómo? y ¿Dónde? este artículo incide sobre la posición frente a los competidores, clientes, proveedores, nuevas entradas y productos sustitutivos; se añaden las especificidades operacionales como el posicionamiento frente a la distribución, producto comercializado, opciones de estandardización versus adaptación, entre otros. Se trata de responder a la siguiente pregunta de los datos disponibles: ¿Cuál ha sido el ritmo de expansión de la hotelería portuguesa en el extranjero? Este proceso tiene lugar esencialmente para el espacio lusófono. Sólo un grupo presenta un posicionamiento multi-mercado, pudiendo ser considerado una multinacional; los restantes tienen un posicionamiento multi-doméstico.

Palabras clave: internacionalización, hoteleria portuguesa, economías emergentes.

\section{INTRODUÇÃO}

O setor do turismo tem vindo em crescendo a nível mundial, com o número de turistas internacionais a chegar aos 1235 milhões em 2016; a despesa média por turista aumentou, tendo no global evoluído de 415 biliões de US\$ em 1995 para 1260 biliões em 2015; representa 1 em cada 11 empregos e vale $10 \%$ do PIB global; a quota de mercado das economias emergentes por sua vez passou de 30\% em 1980 para 44,6\% em 2016 (UNWTO, 2017). Neste contexto, as empresas posicionam-se para acompanhar este crescimento pois, uma vez consolidado o seu mercado interno, procuram também afirmar-se nos novos destinos turísticos.

Relembre-se que a internacionalização em hotelaria foi um processo iniciado pelas grandes cadeias americanas que nas décadas de cinquenta/sessenta se expandiram pelo mundo no sentido de acompanharem os homens de negócios. Porém, com o eclodir da globalização a partir da década de oitenta/noventa e as novas oportunidades das economias 
emergentes, foram muitas as companhias que se lançaram na aventura de estar presente no exterior (Carrasqueira, 1999). Muitas delas, no contexto das cadeias internacionais podem ser consideradas pequenas empresas, provenientes de países que tradicionalmente eram essencialmente recetores de turistas e periféricos no contexto das grandes economias, como é o caso das originárias de Portugal.

A moderna internacionalização da hotelaria portuguesa foi iniciada no final da década de oitenta pelo Grupo Pestana. Outros se lhe seguiram tendo como principal destino os mercados emergentes de África e América do Sul. Recorde-se que a África subsariana, em termos de chegadas de turistas internacionais, cresceu 10,1\% ao ano entre 1980 e 1995 e 7,4\% entre 1995 e 2010; a América do Sul, para os mesmos períodos, cresceu 4,8\% e 4,8\%, respetivamente (UNWTO, 2016). Eram mercados atrativos que despertavam para o turismo.

Por sua vez, a internacionalização das empresas na área industrial tem sido alvo de inúmeros estudos e geração conexa de teorias justificativas. Porém o setor dos serviços e da hotelaria em particular (aqui entendida como soft services no sentido em que requerem a simultaneidade da produção e consumo - Erramilli, 1990), ainda carece de investigação para se conhecer mais de perto esta realidade, nomeadamente no que concerne a pequenas cadeias originárias de países periféricos. É o que se pretende fazer neste artigo no sentido de melhor se conhecer o percurso trilhado pelos grupos/cadeias hoteleiras com origem em Portugal. Recorde-se que Portugal, enquanto destino turístico, recebeu 21,3 milhões de hóspedes em 2016 (INE, 2017), sendo classificado na 14a posição no Travel \& Tourism Competitiveness Report do World Economic Forum (WEF, 2017).

Em concreto, com este paper pretende-se caracterizar a internacionalização da hotelaria portuguesa, através de três aspetos: dimensões da internacionalização; forças competitivas e características da operação no exterior. Acresce responder à seguinte questão: qual tem sido o ritmo de expansão da hotelaria portuguesa?

\section{ENQUADRAMENTO TEÓRICO}

A internacionalização das grandes cadeias hoteleiras tem sido alvo de vários estudos, podendo referir-se os trabalhos de Contractor e Kundu (1998) sobre a entrada em mercados externos através de alianças; Litteljohn, Roper e Altinay (2007), com o levantamento das tendências relativas ao processo de internacionalização através da análise à investigação publicada entre 1996 e 2005; ou, Brokes e Roper (2010) a propósito do modelo organizacional e o efeito no modo de entrada/controlo da marca.

Outros trabalhos, por sua vez, tentam compreender a internacionalização da indústria hoteleira com origem num dado país, podendo referenciar-se como elucidativo o caso da Espanha que, em 2011, colocava cinco cadeias hoteleiras nas trinta primeiras do ranking global da revista Hotels (2011), tendo passado para três cadeias, em 2015, devido à ascensão das cadeias asiáticas (Hotels, 2016). São exemplificativos os trabalhos sobre os "modos de entrada nos mercados externos da indústria hoteleira espanhola" de Rodriguez (2002); "modos de entrada nas Caraíbas das cadeias espanholas com origem nas ilhas Baleares", de Martorell, Mulet e Otero (2013); "desafios estratégicos para a indústria hoteleira espanhola em países 
emergentes para 2020" de Castilho e Quintero (2013); ou "influência da distancia cultural na internacionalização da industria hoteleira espanhola" de Gémar (2014). Acrescem trabalhos específicos sobre as cadeias hoteleiras como é o caso de "estratégia de internacionalização de Sol Méliá para a América Latina" de Álvarez, Cardoza e Diaz (2005).

No que concerne à compreensão da expansão da hotelaria portuguesa no exterior salientam-se os trabalhos sobre "Network relationships and the internationalisation of the tourism economy: The case of portuguese overseas investment in the hotel sector" de Breda, (2010) ou a "internacionalização das empresas de serviços - estudo de caso, aplicado ao grupo Pestana" de Carvalho (2014).

A maioria destes trabalhos foi baseada em análises de dados através da aplicação de modelos quantitativos. Os mesmos podem ser integrados na procura de respostas para os movimentos de internacionalização à volta de questões como: porquê (motivos), onde (países escolhidos), o quê (vantagem competitiva) ou como (modo de entrada). Outros trabalhos sobre internacionalização em hotelaria que se podem referenciar neste contexto são: Barber, Garcia e Darder (2011), Ivanova e Ivanov (2014) e Wulff (2015) nos modos de entrada; Johnson e Vanetti (2005), ou Yang, Luo e Law (2014) na localização dos investimentos; Whitla, Walters e Davies (2007) e Salazar, Moraes e Leite (2012) a propósito dos motivos e vantagens competitivas.

Estas questões integram o modelo designado por dimensões da internacionalização, identificado por autores como Welch e Luostarinen (1988), Chetty (1999) ou Carneiro e Dib (2007). Este modelo em termos gerais também serve de orientação a parte deste trabalho. Todavia, deu-se preferência à obtenção de informação de caráter mais qualitativo junto dos profissionais no terreno (diretores das unidades hoteleiras), o que permitiu também acrescentar uma caracterização de tipo operacional (na lógica da abordagem de Rutherford e Fallon (2007) em Hotel Management and Operations e uma análise de posicionamento setorial usando a estrutura do modelo das cinco forças de Porter (1989) como referido em "The impact of industry force factors on resource competitive strategies on hotel performance" de Takitiyaman, Qu, e Zhang (2010). Acresce uma análise numérica para tipificar o ritmo do processo de internacionalização. Pensa-se, pois, ter conseguido uma análise mais abrangente cuja metodologia se apresenta no ponto seguinte.

\section{METODOLOGIA}

A metodologia utilizada para se alcançar os objetivos propostos tem como principal instrumento a aplicação de um inquérito de recolha de opinião aos responsáveis de unidades hoteleiras no exterior (diretor geral da unidade hoteleira ou diretor de marketing, diretor financeiro ou outro membro da direção - apenas um deveria responder, seguindo esta ordem de prioridade). Metodologia similar foi aplicada no estudo de Breda (2010).

O inquérito a utilizar começou por ser construído a partir de recolha documental incluindo artigos científicos relacionados, capítulos de livros, relatórios de entidades oficiais, documentos em periódicos e disponibilizados na internet, sobre a matéria e por duas entrevistas exploratórias realizadas com elementos da administração de cadeias hoteleiras internacionais. 
Com o primeiro esboço do inquérito elaborado, foi o mesmo enviado para preenchimento a quatro diretores hoteleiros que nos últimos dois anos tinham gerido unidades hoteleiras portuguesas no exterior (dois ainda continuam no exterior e dois regressaram para dirigir hotéis em Portugal); seguiram-se entrevistas com estes últimos para se recolher a opinião sobre o estado do inquérito e sugestões de afinação. Terminou-se assim o pré-teste e considerou-se que reunia condições para um adequado levantamento da informação pretendida.

A população do estudo teve uma fase preparatória que se destinou à identificação das unidades do setor hoteleiro, no qual se utilizaram dois critérios:

- Unidades hoteleiras de grupos nacionais presentes no mercado externo;

- Unidades hoteleiras com operação no exterior há pelo menos dois anos.

Porém, após o levantamento inicial, foi possível constatar a seguinte situação: 92,54\% das mesmas situava-se em África ou na América Latina; os restantes 7,46\% estavam nos Estados Unidos, Europa (quatro), além de um resort na Turquia (Ásia). No seguimento e no sentido de se conseguir uma maior consistência na análise a efetuar, decidiu-se que apenas se iria trabaIhar os hotéis sitos em África/América Latina ou seja, 62 unidades como amostra potencial.

Entretanto, quando se focou a análise nos países selecionados, constatou-se outra característica: quase todos tinham um PIBpc abaixo de $5000 \$$ quando os investimentos foram realizados, o que os colocava na designada BOP - Base of Piramid (Prahalad, 2005) em termos do rendimento dos seus habitantes. Esta situação levou a um cruzamento com outra variável: o IDH - Índice de Desenvolvimento Humano do PNUD (Programa da Nações Unidas para o Desenvolvimento), tendo-se constatado que seis países tinham um IDH baixo ou médio; em consequência decidiu-se excluir quatro países (Argentina, Colômbia e Venezuela - que apresentavam um IDH elevado e/ou um rendimento superior a 9000\$; também a África do Sul foi excluída pois apesar de ter um IDH médio, tinha um rendimento acima de $9500 \$$. Eliminou-se assim mais $6 \%$ de hotéis, o que não se traduzia numa significativa perda pois todos pertencem à mesma cadeia hoteleira, que continua amplamente representada nos restantes países. Outro país também se enquadrava neste padrão; porém era da maior importância nesta análise dado o número elevado no acolhimento do investimento português no exterior em hotéis: o Brasil com 28.

$\mathrm{Na}$ verdade, o Brasil sendo um Estado Federal de dimensão quase continental, a sua divisão administrativa considera cinco grandes regiões, sendo a região Nordeste, que abrange os estados de Pernambuco, Bahia, Piauí, Ceará, Maranhão, Rio Grande do Norte, Alagoas e Sergipe, a que tem mais unidades hoteleiras $(71,4 \%)$, conforme se pode observar na tabela seguinte. Neste contexto, decidiu-se incluir na análise todas as unidades da região do Nordeste Brasileiro, exceto as unidades de S. Paulo, Rio de Janeiro e a do Paraná que operam em contextos muito diferentes. O PIBpc de S. Paulo em 2012 foi de $\$ 39.799$ e o IDH de 0,825; o PIBpc do Rio de Janeiro foi de $\$ 30.088$ e o IDH de 0,826. O Paraná em 2010 tinha um IDH de 0,747 e um rendimento, em termos da metodologia do IDH, de 0,757. 
Tabela 1. Distribuição dos hotéis de grupos portugueses por região - Brasil (2015)

\begin{tabular}{|c|c|c|c|c|c|c|c|}
\hline $\begin{array}{l}\text { Estado } \\
\text { Federal }\end{array}$ & Região & № hotéis & $\%$ & $\begin{array}{l}\text { Estado } \\
\text { Federal }\end{array}$ & Região & № hotéis & $\%$ \\
\hline \multirow{5}{*}{ 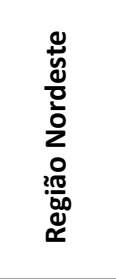 } & Ceará & 3 & $10,7 \%$ & \multirow{5}{*}{$\begin{array}{l}\bar{\Xi} \\
0 \\
0 \\
\stackrel{20}{00} \\
\ddot{\mathscr{0}}\end{array}$} & & & \\
\hline & Pernambuco & 4 & $14,3 \%$ & & Paraná & 1 & $3,6 \%$ \\
\hline & Bahia & 7 & $25 \%$ & & São Paulo & 3 & $10,7 \%$ \\
\hline & Rio Grande do Norte & 5 & $17,9 \%$ & & Rio de Janeiro & 4 & $14,3 \%$ \\
\hline & Maranhão & 1 & $3,6 \%$ & & & & \\
\hline \multicolumn{2}{|c|}{ Subtotal - Região Nordeste } & 20 & $71,4 \%$ & \multicolumn{2}{|c|}{ Subtotal - Região Sul } & 8 & $28,6 \%$ \\
\hline
\end{tabular}

Elaboração própria.

A região do Nordeste é a menos desenvolvida do Brasil, quer em termos de PNBpc, quer no IDH. Investigou-se, então, o ano em que os hotéis ficaram operacionais pelas cadeias portuguesas e obteve-se um PIB médio de \$6.027; o IDH de 2005 (que se situa numa posição intermédia para o início de operação de muitos hotéis - antes e depois - foi de 0,720, correspondente então a uma classificação de desenvolvimento médio (PNUD, 2005).

Em síntese, ficou-se com uma amostra de 49 hotéis, correspondendo a $72 \%$ do total, situados nos seguintes países - a seguir classificados em termos de renda pelo Banco Mundial (World Bank, 2015): em Moçambique e S. Tomé e Príncipe (low income), Marrocos e Cabo Verde (lower middle income), Angola e Brasil - Nordeste, (upper middle income). Ir-se-á classificar todos estes países como "economias emergentes" lato sensu nesta investigação. Pensa-se ser uma amostra equilibrada e homogénea, representativa das cadeias hoteleiras com unidades no exterior, pois apenas uma não está presente nos países selecionados.

No seguimento, enviou-se um e-mail a todos os grupos hoteleiros portugueses a solicitar a colaboração dos quadros de direção dos hotéis a operar nos referidos mercados. Posteriormente, enviou-se o e-mail com o link da página do questionário online e onde se explicava o objetivo do trabalho; disponibilizou-se um endereço eletrónico para esclarecimentos adicionais. Foram feitos três reforços do pedido de colaboração e o questionário foi encerrado no final do segundo mês.

A implementação destes procedimentos permitiu alcançar um total de 34 respostas, uma taxa de resposta de $69 \%$. Tendo em conta que a taxa média de resposta em questionários online (Kaplowitz, Hadlock, e Levine (2004) é de $25 \%$, pode-se afirmar que a taxa obtida superou as expectativas iniciais.

Os questionários permitiram a obtenção de dados confiáveis, pois as respostas estavam limitadas às alternativas mencionadas. Para a maioria das respostas propostas, foi utilizado uma escala intercalar de Likert, na qual se optou por um encore de 1 a 7. De forma suplementar, também foram utilizadas outras escalas como a númerica, de ordem ou rank e de escolha múltipla simples. 


\section{APRESENTAÇÃO DE RESULTADOS}

Quanto aos resultados obtidos, começa-se pelas denominadas dimensões da internacionalização, ou seja, quais as respostas para as seguintes questões: porquê, para onde, o quê e como.

\subsection{Dimensões da internacionalização}

Porquê (motivos) - os principais motivos para o movimento de entrada nos mercados exteriores foram: "capacidade de crescimento do mercado" onde se verificou o investimento, aspeto essencial para se obter retorno positivo; segue-se a "capacidade de atração dos recursos locais", da maior relevância para a instalação do hotel, o que reforça a importância da boa localização para a manutenção duma procura elevada. A "diversificação do risco" aparece a seguir, pois quem tem presença em vários mercados fica menos exposto contra crises do que os concorrentes que apenas fiquem no mercado de origem. É também aqui de referir que um investimento em hotelaria no hemisfério sul permite diversificar problemas de sazonalidade, nomeadamente para cadeias que operem na área dos "resort de sol e mar", pois a época alta é complementar, permitindo ganhos de operação e de geração de fluxos financeiros. Registe-se também a referência à "diversificação da capacidade da empresa" pois quem está em vários mercados/regiões fica mais salvaguardado em termos de eventuais crises e obtém um treino de gestão e uma curva de experiência superior aos concorrentes que apenas operam no mercado doméstico.

Onde (países escolhidos) - excetuando o hotel em Marrocos, todos os outros considerados no inquérito estão situados em países que têm como língua oficial o português. Pode-se, deste modo, afirmar que a internacionalização ocorreu para a proximidade psicológica, com o suporte da língua comum e sistemas sociais, jurídicos e económicos com semelhanças, como referido pela teoria de internacionalização da escola de Uppsala (Johanson e Vahlne, 2009).

Porém, pode-se acrescentar outra linha de identificação no processo de internacionalização da dimensão "onde". O facto de estes hotéis estarem situados em países de rendimento baixo e com um IDH baixo ou médio, tal opção denuncia prudência e um processo de aprendizagem, começando por mercados menos competitivos ou mostra receio/incapacidade de enfrentar a concorrência nos mercados dos países desenvolvidos. Em síntese, pode-se concluir que o processo de internacionalização ocorreu essencialmente para países de língua portuguesa, que na altura do investimento, se podiam considerar como estando em vias de desenvolvimento ou como economias emergentes.

O quê (vantagem competitiva): A "capacidade de diferenciação" foi a principal vantagem apontada, logo seguida do "pertencer a um grupo português", o que atesta a boa receção que as empresas portuguesas têm nestes mercados. Na agregação de conjunto, a "qualidade do serviço" é identificada como um ponto forte. Constata-se, pois que o posicionamento não é feito com base nos preços mas numa estratégia de diferenciação.

Como (modo de entrada) - O estudo indica que o modo de entrada preferido é a aquisição - brown investment - em mais de metade das unidades hoteleiras $(54,5 \%)$, seguido pelo 
investimento de raíz - green-field investment - que representa mais de um quarto (27,3\%). As formas contratuais, relativas aos contratos de gestão, são menores, na ordem dos $17,7 \%$.

Quanto ao regime de propriedade (hotéis adquiridos ou investimento de raíz), 70,6\% dos mesmos são propriedade do grupo na totalidade, denunciando o seu comprometimento e aposta nestes mercados. Os restantes $11,7 \%$ são geridos da seguinte forma: $8,8 \%$ estão em parceria, mas o grupo português é maioritário e apenas num caso $(2,9 \%)$ há parceria em equity com uma empresa local. Estas parcerias realizam-se com o tecido local, nomeadamente na fase inicial e são realizadas com empresas do mesmo ramo (hoteleiro), mas também existem com outros setores como a construção civil.

A forma contratual utilizada é o contrato de gestão, sendo naturalmente nestes casos a propriedade alheia.

Ao contrário do referido pela teoria Uppsala para internacionalização das empresas industriais (Johanson e Vahlne, 1977), neste caso, não se verifica uma expansão pela via contratual mas pela aquisição/criação de ativos. Este é um posicionamento típico das multinacionais (criação de filiais), existindo preferência pela propriedade, sendo explicada pela teoria de internalização (Dunning, 2006). O motivo prende-se com a necessidade de controlo total sobre a operação dentro dos padrões de serviço do grupo. Sendo estes países deficitários a vários níveis (p. ex. recursos humanos qualificados) justifica-se esta opção. Neste aspeto, afastam-se da teoria de Uppsala pois não passam por um processo sequêncial de estágios até à propriedade total (como é comum verificar-se na internacionalização do investimento industrial).

\subsection{A internacionalização enquadrada na estrutura do modelo das cinco forças de Porter}

Recorreu-se ao modelo das cinco forças de Porter (1989) do ponto de vista estrutural dada a sua utilidade para caracterizar um setor, neste caso face ao processo de internacionalização. Veja-se, pois, a percepção dos diretores hoteleiros relativamente aos principais fatores competitivos onde o mercado está inserido:

Rivalidade com concorrentes - salientam que estes procuram fazer a diferenciação com base nos preços pelo que apresentam uma qualidade comparativa inferior; a taxa de ocupação dos concorrentes é considerada menor. Em consequência, pode-se afirmar que os concorrentes não são uma ameaça premente.

Clientes - pertencem maioritariamente à classe média/alta e a fidelidade é considerada elevada. São vistos como tendo poder negocial elevado e são maioritariamente do próprio país, do país de origem da cadeia ou, principalmente, de países vizinhos. Mostra ainda que mesmo em países com um poder de compra geral limitado, há sempre classes que têm um padrão de consumo que permite este tipo de dispêndio. $O$ cliente com origem em Portugal aparece não raras vezes apenas na terceira posição.

Fornecedores - Verifica-se que é difícil trocar de fornecedores por serem insuficientes. O poder negocial dos fornecedores é mais elevado no Brasil e a diferenciação dos produtos e serviços é mais baixa em África. Instados a se pronunciarem sobre a qualidade dos fornecedores, os serviços de segurança, recebem uma classificação média/alta; alimentação e bebidas, 
animação e serviços da administração pública ficam pela média; energia e água, tal como a assistência técnica/manutenção, recebem a classificação inferior.

Novas entradas - Consideram ser provável a abertura de novas unidades, com destaque para investimentos do país anfitrião, que competem com os hotéis portugueses. Todavia, estes potenciais concorrentes não são vistos com excessiva preocupação.

Produtos substitutos - Os produtos substitutos, vistos como ameaça, são o alojamento alternativo à hotelaria nomeadamente o alojamento em casas particulares/local, em crescendo de comercialização online. Acresce a ameaça de perda de clientes para outros destinos, nomeadamente na América Latina.

Sendo uma caracterização breve, pensa-se ser útil acrescentar esta perspetiva de análise por parte dos dirigentes das unidades hoteleiras face às propostas apresentadas no terreno.

\subsection{Características da localização/especificidades da operação}

Instados a caracterizarem o ciclo de vida do produto turístico do país/região em que se insere o hotel, 50\% refere estar em "crescimento acelerado" (desenvolvimento), 10,7\% em "crescimento lento" (envolvimento), 7,1\% numa "fase inicial" (exploratório) ou 7,1\% para "rejuvenescimento" (a recuperar de um período de declínio). A fase da "maturidade" é referida por $17,9 \%$, o que se pode interpretar como sinónimo de alguma estagnação; menos positivo os $7,1 \%$ que declaram estar o destino em "declínio".

Quanto às principais características da região de operação, os aspetos que mereceram nota positiva foram a localização da unidade hoteleira e o clima; os atrativos turísticos disponíveis, a oferta de serviços complementares de restauração e o relacionamento com as autoridades locais e policiais. Os aspetos que obtiveram avaliação menos favorável foram a segurança e a saúde pública, a legislação laboral, a política de impostos e, com pior resultado, a disponibilidade de recursos humanos com formação adequada.

Em termos de estandardização versus adaptação dos hotéis, verifica-se uma clara tendência para a adaptação no caso dos espaços exteriores, restaurante/menu, decoração em geral/espaços interiores e fardamento do pessoal. Onde a adaptação é menor, ou seja, predominando uma certa estandardização, é no relativo aos quartos/comodidades e padrão do serviço, em que tende a persistir os procedimentos tipo da cultura do grupo.

Acresce que foi ainda referido que os hoteis recebem apoio direto a partir de Portugal nas seguintes áreas: tecnologia, decoração e consultadoria.

Relativamente à distribuição, predominam as reservas através de operadores turisticos em $24 \%$ das situações, seguido pelas provindas das agências de viagens online com 19\%; as agências tradicionais recolheram $16,5 \%$ das respostas. A venda direta (call center/telefone) representa $14 \%$. As vendas via site do hotel ficam-se nos $9 \%$, sendo o restante repartido por vendas ao balcão e acordos no âmbito corporate (organismos estatais e empresas). São estes os principais canais identificados como geradores de turistas para as unidades hoteleiras. Verifica-se, pois, uma dependência de intermediários e um volume ainda reduzido dos canais 
diretos. No que concerne à política de preços, a mesma é definida de acordo com as caraterísticas da procura do hotel e preço de mercado praticado a nível local e internacional.

O tipo de produto que é referido como estando na origem da atração dos turistas é o "negócios" com 33\% das respostas, seguido do "sol e mar" com 30\%. Seguem-se o "enquadramento urbano" (15\%) e "paisagístico e de natureza" com $12 \%$ como os mais relevantes.

Os dois principais podem ser explicados pela existência de muitas unidades em cidades capitais na rota do turismo corporate, assim como outros cuja principal atração é a praia, caso dos destinos situados no nordeste brasileiro.

Num enquadramento de países que estão ainda longe de disponibilizarem infraestruturas ao nível dos países desenvolvidos e com uma concorrência entre operadores ainda em fase de estruturação, pensa-se que seria oportuno investigar sobre o nível de cooperação entre os agentes no terreno. Assim, $60 \%$ dos hotéis declara que realiza com regularidade reuniões com hotéis concorrentes, tendo-se identificado dois grandes grupos de atuação que motivam esta colaboração: um na área do marketing, ou seja, a "captação de turistas para a região" e "definição de estratégias de promoção conjunta"; e outro na área operacional, para tratar de questões relacionadas com "o aprovisionamento de alimentação e bebidas" e "animação no hotel". Constata-se, pois, uma necessidade de ganhar escala/dimensão para viabilizar as ações comerciais e possibilitar fornecimentos operacionais de que o mercado ainda é carente, no sentido de ir ao encontro do gosto do turista e do padrão internacional espectável.

\subsection{Características dos respondentes ao inquérito}

Da maioria dos quadros de chefia que responderam ao inquérito, 85,8\% referem pertencer à direção, sendo $53,8 \%$ o diretor geral; os restantes $14,2 \%$ identificam-se como diretor financeiro ou de marketing. Quanto à nacionalidade, $67,8 \%$ são portugueses e os restantes são estrangeiros, com predominância de brasileiros. Por idades, predomina o intervalo 31-40 anos, com 33,3\%, a que se segue 25,9\% com 41-50 anos. Quanto à permanência na empresa, a maioria $(53,7 \%)$, refere estar a trabalhar no grupo/cadeia hoteleira a que o hotel pertence num intervalo entre 1 e 5 anos; 28,6\% entre 6 a 10 anos; $10,7 \%$ entre 11 a 15 anos e $7,1 \%$ entre 16 a 20 anos.

\section{EVOLUÇÃO DA IMPLANTAÇÃO INTERNACIONAL}

Se se ativer à implantação nos mercados internacionais analisados, verifica-se que apenas um grupo está em seis mercados. Dos restantes, dois estão em dois países e os demais em apenas num. Pensa-se, pois, poder-se afirmar que todos os grupos têm um perfil multi-doméstico à exceção do grupo Pestana que pode enquadrar-se na classificação de multinacional, dado ter que trabalhar com múltiplos mercados.

Quanto ao ritmo de implantação, dividiu-se o número de hotéis de cada grupo pelos anos em que estão presentes nos mercados exteriores (a obtenção do valor 1 significa o ritmo de um hotel por ano). Neste sentido, o valor mais elevado pertence ao grupo Pestana com 0,76. De seguida ajustaram-se todos os valores tendo como referência o ritmo do grupo Pestana. 
Nenhum grupo atinge sequer o valor de 0,50 ; apenas o grupo Vila Galé $(0,47)$, Visabeira $(0,46)$ e Luna $(0,44)$ se aproximam da metade em termos de velocidade de internacionalização. Os restantes ficam abaixo destes valores. Em consequência conclui-se que, no geral, se verifica uma estagnação do movimento de internacionalização da hotelaria portuguesa no exterior, apesar da evolução ainda que a um ritmo lento, dos grupos Vila Galé, Visabeira e Luna. Exceção para o grupo Pestana que apresenta um crescimento contínuo e diversificado pelos vários países considerados (apenas não está presente em Angola).

Tabela 2. Evolução das cadeias hoteleiras nas economias emergentes até 2014

\begin{tabular}{|l|c|c|c|c|c|c|}
\hline $\begin{array}{c}\text { Cadeias } \\
\text { hoteleiras }\end{array}$ & $\begin{array}{c}\text { No países } \\
\text { emergentes } \\
\text { em que } \\
\text { estão } \\
\text { presente } \\
\text { hotéis } \\
\text { de cada } \\
\text { cadeia } \\
\text { no } \\
\text { exterior }\end{array}$ & $\begin{array}{c}\text { No } \\
\text { internacionalização }\end{array}$ & $\begin{array}{c}\text { Total de } \\
\text { anos no } \\
\text { exterior }\end{array}$ & $\begin{array}{c}\text { No Hotéis/ } \\
\text { Total anos } \\
\text { no exterior }\end{array}$ & $\begin{array}{c}\text { (No Hotéis/ } \\
\text { Total anos } \\
\text { no exterior) } \\
\text { /0,76 } \\
\text { (referência } \\
\text { Pestana) }\end{array}$ \\
\hline Pestana & 5 & 13 & 1998 & 17 & 0,76 & 1 \\
\hline Vila Galé & 1 & 5 & 2001 & 14 & 0,36 & 0,47 \\
\hline Visabeira & 1 & 6 & 1998 & 17 & 0,35 & 0,46 \\
\hline TD & 2 & 5 & 1986 & 29 & 0,17 & 0,23 \\
\hline AO & 2 & 5 & 1998 & 17 & 0,29 & 0,38 \\
\hline VIP hoteis & 1 & 3 & 2002 & 13 & 0,23 & 0,30 \\
\hline Luna & 1 & 3 & 2006 & 9 & 0,33 & 0,44 \\
\hline Lena & 1 & 2 & 1998 & 17 & 0,12 & 0,15 \\
\hline Béltico & 1 & 2 & 2001 & 14 & 0,14 & 0,19 \\
\hline Tivoli & 1 & 1 & 2006 & 9 & 0,11 & 0,15 \\
\hline D. Pedro & 1 & 1 & 2010 & 5 & 0,20 & 0,26 \\
\hline Sana & 1 & 1 & 2010 & 5 & 0,20 & 0,26 \\
\hline Enotel & 1 & 1 & 2006 & 9 & 0,11 & 0,15 \\
\hline Dorisol & 1 & 1 & 2003 & 12 & 0,08 & 0,11 \\
\hline
\end{tabular}

Elaboração própria.

Nota: não foi possível conferir com exatidão a data do ano de início da internacionalização da cadeia TD. Os hotéis no Brasil da cadeia Tivoli foram, entretanto, vendidos ao Minor Hotel Group da Tailândia.

\section{CONCLUSÃO}

Das 68 unidades hoteleiras pertencentes a grupos hoteleiros portugueses, 49 estão situadas em países/regiões que no momento de realização dos investimentos apresentavam um rendimento que oscilava entre o low income e upper middle income (World Bank, 2015) e um Índice de Desenvolvimento Humano (IDH) médio ou mesmo baixo. Pela sua importância e particularidade, este estudo incide sobre esta realidade, repartindo-se as unidades hoteleiras 
por África (60\% - Moçambique, Cabo Verde, Angola, S. Tomé e Príncipe e Marrocos) e América do Sul (40\% - nordeste do Brasil). Classificaram-se estes países, para a presente investigação, como economias emergentes lato sensu.

Excetuando Marrocos, todos os demais países têm como língua oficial o português, pelo que se pode afirmar, na linha da escola de Uppsala, que a internacionalização ocorreu para a proximidade psicológica. Porém, na forma de abordar o mercado não seguiram um processo de estágios, por etapas, tendo antes optado pelo Investimento Direto com detenção da propriedade, o que remete para a teoria da internalização. Tal posicionamento é próprio da internacionalização das empresas de serviços e surge da necessidade imperiosa de exercer um controlo estreito sobre a qualidade do serviço a oferecer, aspeto relevante da manutenção da competitividade.

O principal motivo para a internacionalização foi a capacidade de crescimento potencial destes mercados, apresentados como em fase de crescimento na sua maioria, do ponto de vista do ciclo turístico. Estas economias conferem uma vantagem competitiva aos hotéis com origem em grupos portugueses dado a língua comum, hábitos e costumes partilhados ao longo do contacto secular e a capacidade de diferenciação face à oferta existente.

Em consequência, a apreciação dos diretores destes hotéis sobre o enquadramento competitivo envolvente é de não excessiva preocupação face à concorrência; de boa fidelidade dos clientes pertencentes a classes média/alta; de ser necessário uma melhoria da fiabilidade dos fornecedores; de ser potencial a entrada de novos concorrentes e de preocupação com produtos substitutos, como o alojamento alternativo vendido online.

Em termos operacionais, nota menos positiva para a segurança e saúde pública, legislação laboral, política de impostos e disponibilidade de recursos humanos com formação adequada. Há adaptação nos hotéis de aspetos como os espaços exteriores, restauração, decoração e fardamento do pessoal. Há estandardização nos quartos/comodidades e nomeadamente na qualidade do serviço, que obedece à cultura do grupo/cadeia. Há apoio direto da base em Portugal no caso da tecnologia, decoração e consultadoria.

Na distribuição verifica-se uma dependência significativa dos intermediários turísticos, nomeadamente operadores e agências de viagens (OTA e clássicas); o volume dos canais diretos tem espaço para progredir. A política de preços é definida de acordo com as características do hotel e preço praticado a nível local e internacional.

Em síntese, pode-se concluir que a hotelaria portuguesa encontrou no espaço lusófono o local preferido para a sua internacionalização, evitando o confronto com as grandes marcas hoteleiras internacionais. Porém, a maioria das cadeias está presente apenas num país ou dois no máximo, assumindo um posicionamento que se classifica como multi-doméstico; apenas o grupo Pestana tem um posicionamento multi-mercado, podendo ser considerado uma multinacional. Quanto ao ritmo de internacionalização e com exceção do grupo Pestana, verifica-se também alguma cristalização, menos acentuada nos grupos Vila Galé, Visabeira e Luna, que continuaram o processo de internacionalização. Nomeadamente este último ponto carece de estudos subsequentes para se tentar compreender os motivos desta estagnação. 
Uma referência final para a necessidade de se aprofundar a investigação sobre o tema da internacionalização em hotelaria, pois o turismo é uma área em crescimento à escala internacional e o alojamento uma das suas principais áreas. Todavia estes são processos complexos, que requerem disponibilidade em termos de capital financeiro para suportarem períodos relativamente longos de retorno do investimento e capital humano para operar em países de costumes e hábitos diferentes. Logo, novos estudos ao nível do financiamento dos investimentos ou de gestão de expatriados, por exemplo, afiguram-se como bons temas para aumento do conhecimento sobre o assunto. Uma limitação do estudo no conhecimento da internacionalização da hotelaria portuguesa é se ter cingido aos mercados emergentes. Todavia, verifica-se uma recente tendência de internacionalização para os mercados desenvolvidos da Europa e Estados Unidos, o que representará uma nova oportunidade para investigação futura e que merecerá a sua devida atenção.

\section{Implicações para a teoria e industria}

Do ponto de vista teórico, no presente trabalho salienta-se nomeadamente a especificidade detetada na internacionalização das empresas de hotelaria. De facto, na escolha dos países para onde internacionalizar usam da prudência já identificada nos modelos comportamentais (proximidade psicológica); porém, na forma como entram no mercado, preferem o investimento direto (aquisição ou investimento de raiz), próprio dos modelos ditos económicos.

O motivo para esta especificidade prende-se com a necessidade imperiosa de controlar e manter a qualidade do serviço, pilar fundamental da sua competitividade. Afastam-se assim das características da internacionalização de tipo industrial em que a abordagem ao mercado é feita de forma sequencial, através das formas contratuais, aparecendo o investimento direto, em regra, como a fase final do processo.

Para a industria hoteleira, este trabalho afigura-se útil no sentido em que se procurou caracterizar a internacionalização da hotelaria portuguesa através dum levantamento junto dos diretores dos hotéis abrangidos na amostra. Obtivemos assim uma postura do posicionamento de tipo operacional e competitivo, junto de profissionais no terreno, cujas respostas, pensamos, podem ajudar a preparar processos de internacionalização e evitar erros, que, não raras vezes, se traduzem em problemas financeiros complexos.

A confirmação do posicionamento teórico acima mencionado, nomeadamente quando efetuado para mercados emergentes, é outro tema que se propõe para futuras investigações.

\section{REFERÊNCIAS BIBLIOGRÁFICAS}

Álvarez, J., Cardoza, G., e Diaz, R. (2005). Estrategia de internacionalización de Sol Meliá em America Latina. Academia, Revista Latinoamericana de Administración, 35(2), 107-134.

Barber, J., Garcia, C., e Darder, F. (2011). Entry mode choice in the internationalization of the hotel industry: A holistic approach. The Services Industries Journal, 31(1), 107-122.

Breda, Z. (2010). Network relationships and the internationalisation of the tourism economy: The case of portuguese overseas investment in the hotel sector. (Dissertação para 
obtenção do grau de doutor em Turismo), Universidade de Aveiro, Aveiro. http://ria. ua.pt/bitstream/10773/1856/1/2010000691.pdf, acedido em 17-06-2016.

Brokes, M., e Roper, A. (2010). The impact of entry modes on the organisational design of international hotel chains. The Services Industries Journal, 30(9), 1499-1512.

Carneiro, J., e Dib, L. (2007). Avaliação comparativa do escopo descritivo e explanatório dos principais modelos de internacionalização de empresas. Internext-Revista de Negócios Internacionais da ESPM, SP, 2(1), 1-25.

Carrasqueira, H. (1999). Internacionalização das empresas de turismo - Novas tendências. Colecção Estudos Turísticos, Ed. ICEP.

Carvalho, L. (2014). Internationalization of service-oriented companies: Case study research into hospitality group. Tourism Management Studies, 10 (special issue), 169-173.

Castilho, G., e Quintero, J. (2013). Retos estratégicos de la industria hotelera espanola del siglo XXI: Horizonte 2020 en paises emergentes. Tourim Management Studies, 9(2), 13-20.

Chetty, S. (1999). Dimensions of internationalization of manufacturing firms in the apparel industry. European Journal of Marketing, 33(1-2), 121-142.

Contractor, F., e Kundu, S. (1998). Modal choice in a world of alliances: Analyzing organizational forms in the international hotel sector. Journal of International Business studies, 29(2), 325-357.

Dunning, J. (2006). Space location and distance in international business activities. Paper presented at annual meeting of European Academy of International Business, Fribourg, Switzerland.

Erramilli, M. (1990). Entry mode choice in service industries. International Marketing Review, $7(5), 50-62$.

Gémar, G. (2014). Influence of cultural distance on the internationalisation of spanish hotel companies. Tourism \& Management Studies, 10(1), 31-36.

Hotels (2011). Hotels 325. www.hotelsmag.com, September 2011, acedido em 06-01-2016.

Hotels (2016). Hotels 325. The winds of change. www.hotelsmag.com, July-August 2016, acedido em 14-06-2017.

INE (2016). Atividade turística manteve resultados positivos em 2015. Estatísticas do Turismo - série Destaque, publicado a 28-07-2016. https://www.ine.pt/xportal/ xmain?xpid=INE\&xpgid=ine destaques\&DESTAQUESdest boui=249991832\&DESTAQUESmodo=2\&xlang=pt, acedido em 14-06-2017.

INE (2017) Estatísticas do Turismo 2016. Edição de 2017. https://www.ine.pt/xportal/ xmain?xpid=INE\&xpgid=ine publicacoes\&PUBLICACOESpub boui=277048338\&PUBLICACOEStema $=55581 \&$ PUBLICACOESmodo=2acedido em 06-01-2019.

Ivanova, M., e Ivanov, S. (2014). Hotel chains' entry mode in Bulgaria. Anatolia, 25(1), 131-135. Johnson, C., e Vanetti, M. (2005). Locational strategies of international hotel chains. Annals of Tourism Research, 32(4), 1077-1099.

Johanson, J., e Vahlne. J. (1977). The internationalization process of the firm-a model of knowledge development and increasing foreign market commitments. Journal of International Business Studies, 8(1), 23-32.

Johanson, J., e Vahlne, J. (2009). The Uppsala internationalization process revisited: From liability of foreignness to liability of outsidership. Journal of International Business Studies, $40,1141-1431$. 
Kaplowitz, M., Hadlock, T., e Levine, R. (2004). A comparison of web and mail survey response rates. Public Opinion Quarterly, 68(1), 94-101.

Litteljohn, D., Roper, A., e Altinay, L. (2007). Territories still to find - the business of hotel internationalization. International Journal of Service Industry Management, 18(2), 167-183.

Martorell, O., Mulet, C., e Otero, L. (2013). Choice of market entry mode by Balearic hotel chains in the Caribbean and Gulf of Mexico. International Journal of Hospitality Management, 32, 217-227.

PNUD (2005). Relatório do Índice de Desenvolvimento Humano. http://hdr.undp.org/sites/ default/files/hdr15 overview pt.pdf, acedido em 07-04-2016.

Porter, M. (1989). Vantagem competitiva. Campus: Rio de Janeiro.

Prahalad, K. (2005). A riqueza das nações na base da pirâmide: Como erradicar a pobreza com o lucro. Bookman: Porto Alegre.

Rodriguez, A. (2002). Determining factos in entry choice for international expansion: The case of the spanish hotel industry. Tourism Management, 23(6), 597-607.

Ruterford, D., e Fallon, M. (2007). Hotel management and operations. $4^{\text {th }}$ edition. John Wiley \& Sons: New Jersey.

Salazar, S., Moraes, A., e Leite, P. (2012). Processo de internacionalización de servicios - Un estúdio en una cadena de restaurantes del nordeste brasileño. Estudios y Perspetivas en Turismo, 21(4), 1035-1049.

Takitiyaman, P., Qub, H., e Zhangc, H. (2010). The impact of industry forces factors on resource competitive strategies on hotel performance, International Journal of Hospitality Management, 30(3), 648-657.

UNWTO (2016). UNWTO Annual Report 2015, Madrid. http://www2.unwto.org/publication/ unwto-annual-report-2015, acedido em 18-08-2017.

UNWTO (2017). UNWTO Annual Report 2016, Madrid. http://cf.cdn.unwto.org/sites/all/files/ pdf/annual report 2016 web 0.pdf, acedido em 07-08-2017.

WEF (2017). Travel \& Tourism Competitiveness Report do World Economic Forum. http:// reports.weforum.org/travel-and-tourism-competitiveness-report-2015/economy-rankings/, acedido em 18-08-2017.

Welch, R., e Luostarinen, L. (1988). Internationalization: Evolution of a concept. Journal of General Management, 14(2), 36-64.

Whitla, P., Walters, P., e Davies, H. (2007). Global strategies in the international hotel industry. Hospitality Management, 26, 777-791.

World Bank. (2015). Country and Lending Groups. http://data.worldbank.org/about/country-and-lending-groups\#IDA, acedido em 23-02-2016.

Wulff, J. (2015). Empirical research in foreign market entry mode. (Phd thesis), Aarhus University, Aarhus. http://pure.au.dk/portal/files/85180694/PhD thesis Jesper Nydam Wulff. pdf, acedido em 18-02-2016.

Yang, Y., Luo, H., e Law, R. (2014). Theoretical, empirical, and operational models in hotel location research. International Journal of Hospitality Management, 36, 209-220. 